\title{
Comparison of Effects of Famotidine on Vagally and Field-Electrically Stimulated Acid Secretion in the Isolated Mouse Whole Stomach
}

\author{
Masayuki Yamamoto, Shingo Yano and Kazuo Watanabe* \\ Laboratory of Chemical Pharmacology, Department of Drug Evaluation and Toxicological Sciences, Faculty of Pharmaceutical Sciences, \\ Chiba University, I-33, Yayoi-cho, Inage-ku, Chiba 263, Japan \\ Received June 26, 1995 Accepted September 4, 1995
}

\begin{abstract}
Effects of famotidine on neuronally evoked acid secretion were investigated by means of vagal (at the lower esophagus level) and field-electrical stimulation (around the stomach) in the isolated mouse whole stomach preparation. Each of the electrical stimulations caused a frequency-dependent ( 1 to $20 \mathrm{~Hz}$ ) increase in acid output, and the secretory response was abolished by tetrodotoxin or atropine. In the case of field stimulation, the acid secretion was not completely inhibited by hexamethonium. When $10 \mathrm{~Hz}$ frequency was applied with either vagal or field-electrical stimulation, the acid secretion was only partly inhibited by famotidine at doses of up to $30 \mu \mathrm{M}$. In contrast, the acid response to $2 \mathrm{~Hz}$ stimulation was almost completely inhibited by $1 \mu \mathrm{M}$ famotidine. In the presence of neostigmine $(30 \mathrm{nM})$, the $2 \mathrm{~Hz}$ vagally stimulated acid secretion became partly resistant to the effect of famotidine $(10 \mu \mathrm{M})$. These results suggest that both vagally and field-electrically stimulated acid secretions have essentially the same characteristics and that the secretory mechanism through histamine release is exclusively dominant with weak stimulation, while the cholinergic mechanism on parietal cells is sufficient for reaching the maximal secretory response with strong stimulation.
\end{abstract}

Keywords: Gastric acid secretion, Vagus nerve, Histamine, Famotidine, Stomach (mouse isolated)

Physiological roles of endogenous histamine in mediating vagally stimulated acid secretion have been widely studied for more than 50 years (1). At present, the most accepted theory is the so-called "transmission hypothesis" that muscarinic receptors exist on both parietal cells and histamine containing cells, but the receptor that contributes to vagally stimulated acid secretion is mainly on the histamine containing cells and is not on the parietal cells under physiological conditions $(2,3)$. As for localization of the muscarinic receptor, receptor binding and functional studies (4-6) demonstrated that parietal cells possess muscarinic receptors.

The isolated mouse whole stomach preparation is known to be most suited for neuropharmacological study of acid secretory regulation. This preparation is especially beneficial for elucidating the acid secretory mechanisms in the whole tissue level because it keeps cell-to-cell interactions and autonomic nerves intact ( $7-9)$. Angus and Black (10) first succeeded in measuring the acid secretion in response to electrical field stimulation in mice. They,

\footnotetext{
* To whom correspondence should be addressed.
}

together with other researchers, reported that the acid secretion evoked by field stimulation was completely inhibited by histamine $\mathrm{H}_{2}$-antagonists such as metiamide $(10)$, cimetidine (11) and tiotidine $(8,12)$, suggesting that the neuronally evoked acid secretion is via histamine release. Furthermore, Black and his co-workers found that the acid response to a combination of field stimulation and physostigmine, an acetylcholine esterase inhibitor, was refractory to $\mathrm{H}_{2}$-antagonist treatment $(3,12)$. They proposed that the muscarinic receptor density on histamine containing cells is higher than the density on parietal cells. However, our previous study, where vagal stimulation was applied instead of field stimulation in the isolated mouse whole stomach, demonstrated that famotidine, an $\mathrm{H}_{2}$-antagonist, only partly inhibited the acid secretory response to electrical vagal stimulation without physostigmine (13). This finding suggests the possibility that the major secretory mechanism operating under vagal stimulation may be direct activation of muscarinic receptors on parietal cells.

To elucidate precise involvement of histamine in neuronally evoked acid secretion, we investigated the effects 
of famotidine on vagally and field-electrically stimulated acid secretory responses by using both types of submaximal and supramaximal electrical stimulations.

\section{MATERIALS AND METHODS}

\section{Materials}

Drugs used were as follows: tetrodotoxin (Sankyo, Tokyo), atropine sulfate and histamine dihydrochloride (Nacalai Tesque, Inc., Kyoto), hexamethonium dichloride (Wako Pure Chemical Industries, Osaka), neostigmine bromide (Tokyo Kasei Kogyo, Tokyo), bethanechol chloride and famotidine (Sigma Chemical Co., St. Louis, MO, USA). Omeprazole was kindly given to us by Yoshitomi Pharmaceutical (Osaka). All other chemicals used were of special grade.

Methods for preparing the isolated mouse whole stomach and measurement of acid secretion

Male mice, ddY strain (5-6-week-old, weighing 22-32 g; Japan SLC Inc., Shizuoka), that were fasted for 3-4 hr but allowed free access to water were used. Isolated whole stomach was prepared as described in our previous report (13). Briefly, under urethane $(18 \mathrm{mg} / 10 \mathrm{~g}$, i.p.) anesthesia, the isolated stomach was placed in a $20-\mathrm{ml}$ organ bath containing a serosal side nutrient solution $(128 \mathrm{mM} \mathrm{NaCl}$, $4.8 \mathrm{mM} \mathrm{KCl}, 1.2 \mathrm{mM} \mathrm{MgSO}_{4}, 1.3 \mathrm{mM} \mathrm{CaCl}, 30 \mathrm{mM}$ glucose and $10 \mathrm{mM}$ HEPES; $\mathrm{pH} 7.0$ adjusted with $\mathrm{NaOH}$ and gassed with $95 \% \mathrm{O}_{2}$ and $5 \% \mathrm{CO}_{2}$ ) that was kept at $37^{\circ} \mathrm{C}$. The stomach lumen was perfused at the rate of 1 $\mathrm{ml} / \mathrm{min}$ with a mucosal site nutrient solution $(137 \mathrm{mM}$ $\mathrm{NaCl}, 4.8 \mathrm{mM} \mathrm{KCl}, 1.2 \mathrm{mM} \mathrm{MgSO}$, $1.3 \mathrm{mM} \mathrm{CaCl}_{2}, 30$ $\mathrm{mM}$ glucose; $\mathrm{pH} 5.0$ adjusted with $0.1 \mathrm{~N} \mathrm{HCl}$ and gassed with $100 \% \mathrm{O}_{2}$ ). Acid output was measured by titrating hydrogen ion with $1 / 500 \mathrm{~N} \mathrm{NaOH}$ to the end point of $\mathrm{pH}$ 5.0 (initial $\mathrm{pH}$ of mucosal solution) with an automatic titrator (HM-5ES and HSM-10A; Toa Electronics Co., Tokyo). The digital pulse ( $2 \mu \mathrm{l} /$ pulse) from the titrator was sent to a personal computer (FM-77; Fujitsu, Tokyo) equipped with a pulse counter (developed by our laboratory).

\section{Vagal stimulation and experimental designs}

Vagal stimulation was applied via a pair of platinum electrodes (wire diam.: $0.25 \mathrm{~mm}$, ring diam.: $1.2 \mathrm{~mm}$, and distance between two electrodes: $1.5 \mathrm{~mm}$ ) at the position of the lower esophagus as previously reported (13). Square-wave pulses were delivered from an electronic stimulator (SEN-7203; Nihon Kohden, Tokyo). After equilibration for $30 \mathrm{~min}$, the 1st vagal stimulation was applied $(10 \mathrm{~Hz}, 0.3 \mathrm{msec}, 10 \mathrm{~V}$, for $5 \mathrm{~min})$. Acid secretion was initiated within $10 \mathrm{~min}$ after the onset of stimulation. At 30 min after the onset of the 1st vagal stimulation, the 2nd vagal stimulation (the same condition with the 1 st vagal stimulation) was applied. The response to the 2nd vagal stimulation was used as a control response for the following treatments. Thirty minutes after the 2 nd vagal stimulation, the 3 rd vagal stimulation $(1-20 \mathrm{~Hz})$ or a secretagogue (histamine or bethanechol) was applied. In the case of field stimulation, a pair of ring platinum electrodes for field stimulation (wire diam.: $0.25 \mathrm{~mm}$, ring diam.: $1.2 \mathrm{~mm}$ ) were placed at either side of the stomach ( $2 \mathrm{~mm}$ apart from the stomach wall) after the 2 nd vagal stimulation, and the field stimulation $(1-20 \mathrm{~Hz}, 0.3$ $\mathrm{msec}, 20 \mathrm{~V}$, for $5 \mathrm{~min}$ ) was applied $30 \mathrm{~min}$ later. Each test drug was applied at $10 \mathrm{~min}$ before the $3 \mathrm{rd}$ vagal or field stimulation or secretagogue treatment. In some cases, the 3rd vagal stimulation was applied $70 \mathrm{~min}$ after the 2 nd stimulation, and famotidine was applied $50 \mathrm{~min}$ before the 3rd stimulation. In some cases, omeprazole was applied at the end of experiments. The total volume of drug solution added to the $20 \mathrm{ml}$ organ bath did not exceed 0.4 $\mathrm{ml}$. Famotidine was prepared in saline after being dissolved with a small volume of $0.1 \mathrm{~N} \mathrm{HCl}$. Omeprazole was prepared in $50 \%$ dimethyl sulfoxide (DMSO) solution, and the final concentration of DMSO, which was less than $1 \%$ in the organ bath, did not affect basal or secretagogue-induced acid secretion. All other drugs were dissolved in saline.

\section{Evaluation of acid secretory response}

The time course of acid output was corrected for the time delay due to a dead volume of about $3 \mathrm{ml}$ in the tubing from the stomach to the $\mathrm{pH}$ electrode. Acid secretory response to electrical stimulation or secretagogues was expressed as the net increase in acid output over basal acid output for $10 \mathrm{~min}$ before the start of stimulation. If the 2nd vagal response was less than $1 \Delta \mu \mathrm{Eq} \mathrm{H}^{+}$/stimulation, the stomach preparation was considered not to be suitable for experiments (such preparations were less than $2 \%$ of the total). The effect of each test drug on vagally or field-electrically stimulated acid secretion was calculated as the ratio to the 2 nd vagally evoked response and expressed as a percentage. The maximal 10 -min secretory response to each secretagogue that occurred within 40 min after drug application was referred to as the drug's control secretory action. Furthermore, the value was expressed as a percentage of the response to the 2nd vagal stimulation according to the previous report (13).

\section{Statistics}

All data are expressed as the mean \pm S.E.M. of 4-5 experiments. Statistical analysis was performed by Student's $t$-test (unpaired, two-tailed) or one-way analysis of variance (ANOVA, followed by Dunnett's test). Statistical significance was evaluated at a $P$ value of not 
more than 0.05 . The $\mathrm{pA}_{2}$ values of atropine and famotidine were calculated from the dose-response curves for each secretagogue in the presence or absence of the respective antagonist.
RESULTS

Characteristics of basal and vagally stimulated acid secretion

The basal secretory rate of acid was 50 to $100 \mathrm{nEq} \mathrm{H}^{+}$

A

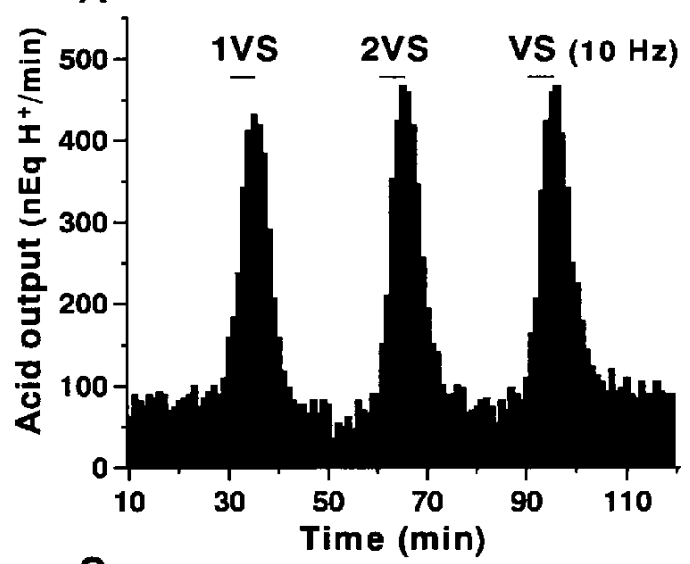

B

C

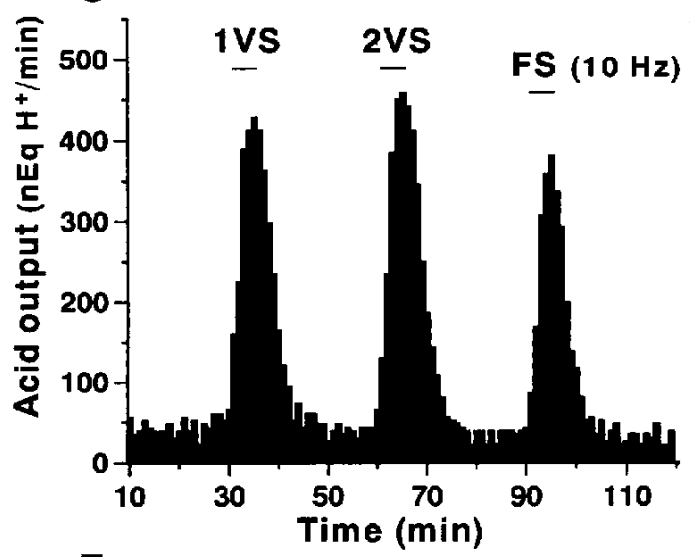

E
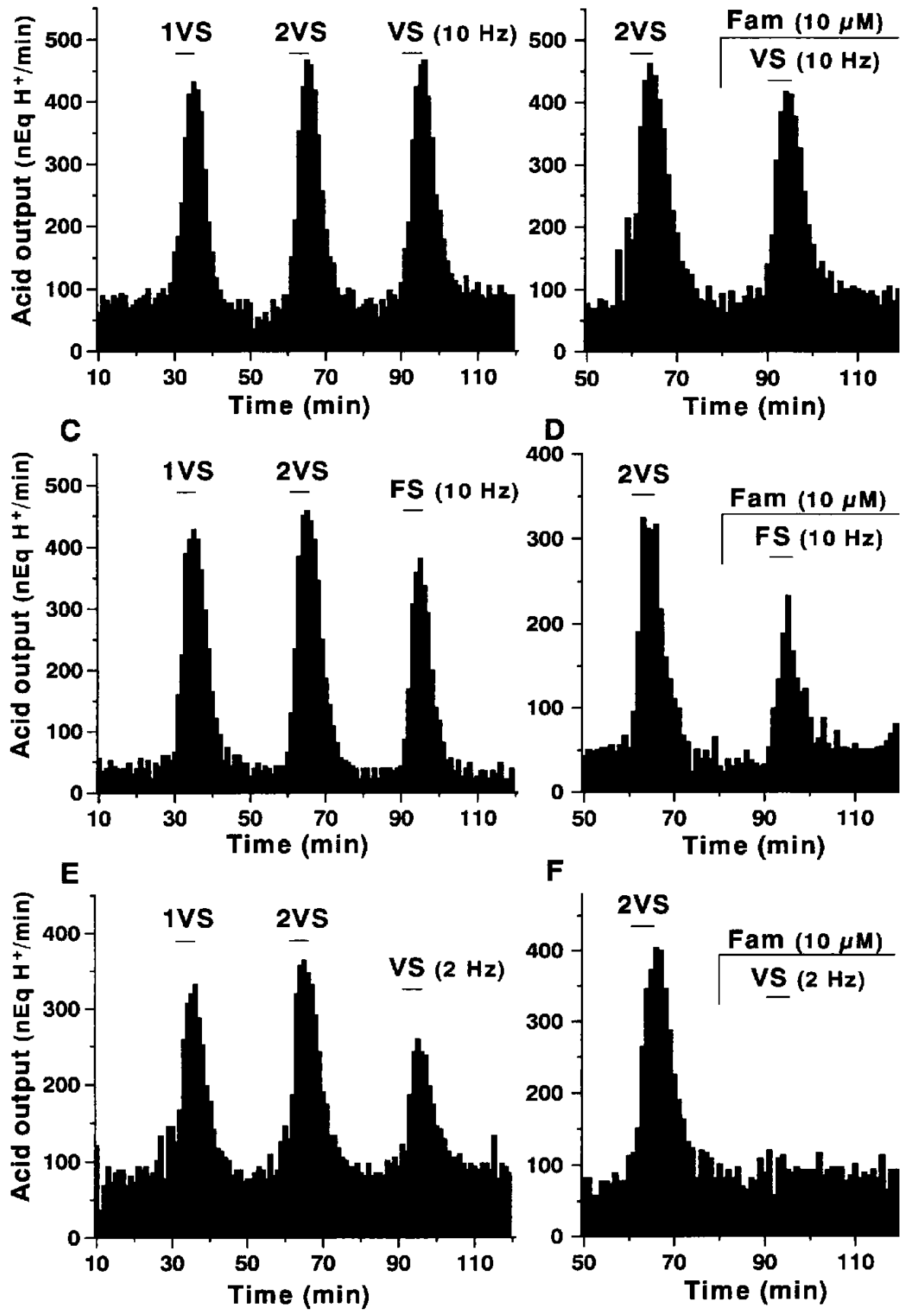

D

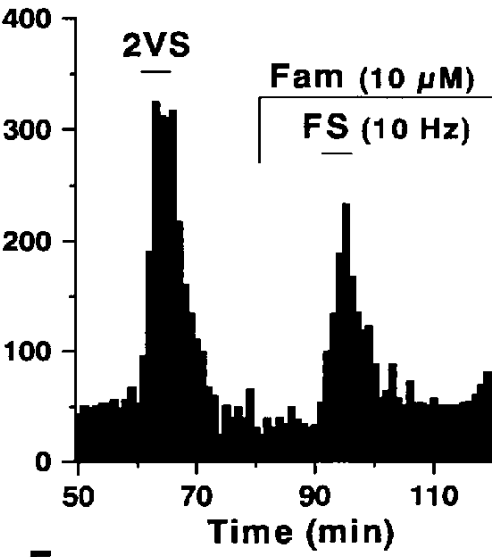

$\mathbf{F}$

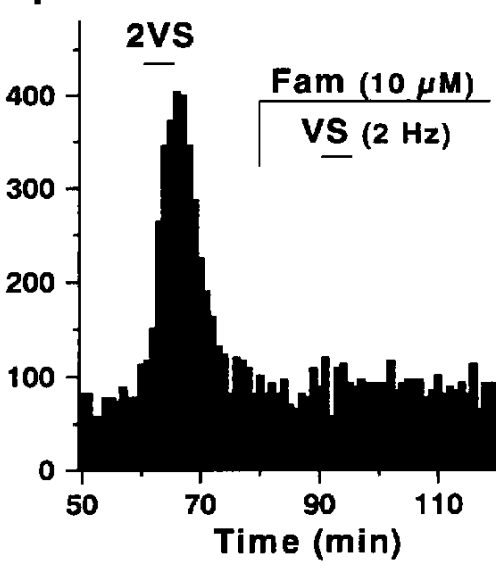

Fig. 1. Typical patterns of acid secretory response induced by vagal and field-electrical stimulation in the isolated mouse whole stomach. The histogram represents the acid output for $1 \mathrm{~min}$. The $1 \mathrm{st}$ and the 2 nd vagal stimulations (1VS and $2 \mathrm{VS} ; 10 \mathrm{~Hz}, 0.3$ $\mathrm{msec}, 10 \mathrm{~V}$, for $5 \mathrm{~min}$ ) were applied in all preparations, and the 3rd vagal stimulation (VS) or field stimulation (FS) was applied at the indicated stimulation frequency. B, D and F: Famotidine (Fam) treatment was performed 15 min after the end of the 2nd vagal stimulation, and VS or FS was applied $10 \mathrm{~min}$ after the Fam addition. Results are summarized in Figs. 3 and 4. 
$/ \mathrm{min}$, and the level of the basal output lasted at least $3 \mathrm{hr}$ without increasing or decreasing. This basal level was completely abolished by $30 \mu \mathbf{M}$ omeprazole, a proton pump inhibitor, suggesting that the monitoring of acid output means only monitoring proton output from parietal cells without other organic acids or carbon dioxide in the organ bath or atmosphere. Some typical patterns of acid secretion induced by electrical stimulation are shown in Fig. 1. In vagally stimulated acid secretion, a measurable change in acid secretion began in 2 min after the onset of the 1st vagal stimulation, and the peak acid secretion $\left(200-400 \mathrm{nEq} \mathrm{H}^{+} / \mathrm{min}\right)$ took place after 5-7 $\mathrm{min}$, then gradually decreased, and disappeared in about $15 \mathrm{~min}$ after the stop of vagal stimulation. The responses to the 2 nd and the 3rd stimulation were almost the same, and they were greater than the 1 st response (the peak value: $300-500 \mathrm{nEq} \mathrm{H} \mathrm{H}^{+} / \mathrm{min}$ ). On the other hand, when the stomach isolation was performed after killing the animals by bleeding, the 2 nd vagally stimulated acid secretion was significantly lower than in the case of isolation under anesthesia (the former, $1.25 \pm 0.20 \Delta \mu \mathrm{Eq} \mathrm{H}^{+}$ /stimulation, $\mathrm{N}=5$ versus the latter, $2.62 \pm 0.21 \Delta \mu \mathrm{Eq}$ $\mathrm{H}^{+}$/stimulation, $\mathrm{N}=5, \mathrm{P}<0.01$ ). The same phenomenon was also seen in $100 \mu \mathrm{M}$ histamine-induced acid secretion (isolation under anesthesia, $3.65 \pm 0.29 \Delta \mu \mathrm{Eq} \mathrm{H} \mathrm{H}^{+} / 10$ $\min , \mathrm{N}=5$ versus isolation after killing, $1.57 \pm 0.33 \Delta \mu \mathrm{Eq}$ $\mathrm{H}^{+} / 10 \min , \mathrm{N}=5, \mathrm{P}<0.01$ ).

\section{Secretagogue induced acid secretion}

Typical patterns of acid secretion induced by bethanechol and histamine and their dose-response curves are shown in Fig. 2. The bethanechol induced acid secre-
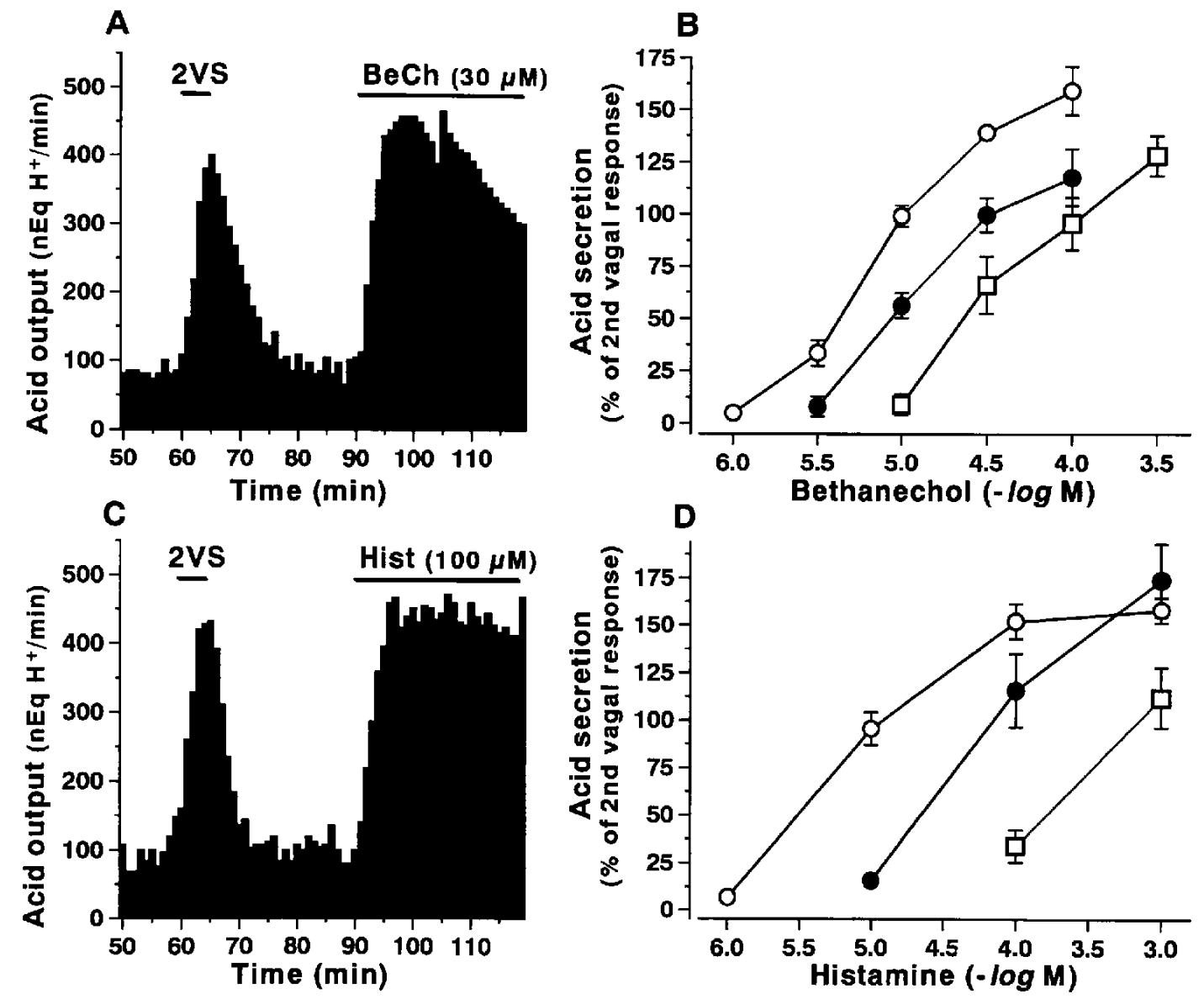

Fig. 2. Bethanechol or histamine induced acid secretion and effect of the respective receptor antagonist in the isolated mouse whole stomach. Bethanechol (BeCh) or histamine (Hist) was applied $25 \mathrm{~min}$ after the end of the 2nd vagal stimulation (2VS), and atropine (Atr) or famotidine (Fam) was applied $10 \mathrm{~min}$ before the BeCh or Hist addition, respectively. A and C: Typical patterns of acid secretion induced by BeCh or Hist without antagonist. The histogram represents the acid output for 1 min. $\mathrm{B}$ and D: Dose-response curves represent the acid secretion induced by $\mathrm{BeCh}$ or Hist with or without the respective receptor antagonist. B: Control (O); Atr, $30 \mathrm{nM}(\bigcirc)$; Atr, $100 \mathrm{nM}(\square)$. D: Control (O); Fam, $0.3 \mu \mathrm{M}(\bigcirc)$; Fam, $1 \mu \mathrm{M}(\square)$. Each value is assessed as a percentage of the $2 \mathrm{VS}$ response. Results each represent the mean \pm S.E.M. of $4-5$ experiments. The averaged increases in acid secretion by $2 \mathrm{VS}$ in all groups were $1.93-3.14 \Delta \mu \mathrm{Eq} \mathrm{H} \mathrm{H}^{+}$/stimulation. 
tion was immediately initiated after application. In most cases, the increased response was gradually reduced 20 to $40 \mathrm{~min}$ after treatment. The doses of $1 \mu \mathrm{M}$ to $100 \mu \mathrm{M}$ bethanechol evoked an increase in acid secretion in a concentration-dependent manner. Atropine (30 and 100 nM) shifted the dose-response curve of bethanechol induced acid secretion rightward, and the $\mathrm{pA}_{2}$ value was $7.82(7.60-8.01 ; 95 \%$ confidence limits), which was consistent to the value reported by others $\left(\mathrm{pA}_{2}=7.65\right)$ (14). However, this value was significantly lower than the $\mathrm{pA}_{2}$ value $8.98(8.63-9.33)$ that was estimated against contraction of the guinea pig longitudinal ileum by our own study.

The histamine induced acid secretion began slightly later than the bethanechol response and was unchanged for at least 30-40 min after treatment. The doses of $1 \mu \mathrm{M}$ to $1 \mathrm{mM}$ histamine evoked an increase in acid secretion in a concentration dependent manner. Famotidine $(0.3$ and $1 \mu \mathrm{M}$ ) shifted the dose-response curve of histamineinduced acid secretion rightward, and the $\mathrm{pA}_{2}$ value was 7.38 (7.04-7.69), which was consistent to the value reported by others $\left(\mathrm{pA}_{2}=7.50\right)(15)$.

The maximal responses to bethanechol and histamine

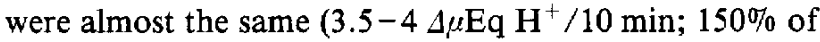
the 2 nd vagal response).

Effects of autonomic drugs on vagally and field-electrically stimulated acid secretion

Frequency dependent acid secretory responses to the 3rd vagal or field-electrical stimulation are shown in Fig. 3. The frequency dependent increase was observed at 1 $\mathrm{Hz}$ to $5 \mathrm{~Hz}$, and the $20 \mathrm{~Hz}$ response was similar to the 5 to $10 \mathrm{~Hz}$ responses in both types of nerve stimulation, indicating that the $2 \mathrm{~Hz}$ or $10 \mathrm{~Hz}$ stimulation evokes a submaximal or a supramaximal acid secretory response,

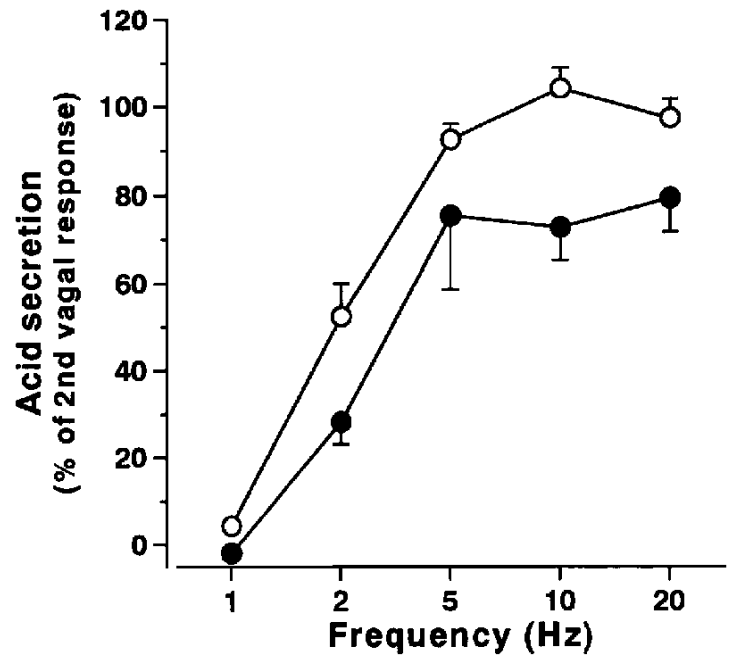

Fig. 3. Frequency-dependent curves of vagally and field-electrically stimulated acid secretion in the isolated mouse whole stomach. The 3rd vagal stimulation ( 1 to $20 \mathrm{~Hz}$ ) or field-electrical stimulation (1 to $20 \mathrm{~Hz}$ ) was applied $25 \mathrm{~min}$ after the end of the 2nd vagal stimulation (2VS; $10 \mathrm{~Hz}$ in common). Each curve represents the acid secretion induced by vagal $(O)$ or field-electrical $(O)$ stimulation with changing frequency. Each value is assessed as a percentage of the 2VS response. Results each represent the mean \pm S.E.M. of 4 experiments. The averaged increases in acid secretion by $2 \mathrm{VS}$ in all groups were $2.01-3.20 \Delta \mu \mathrm{Eq} \mathrm{H}{ }^{+} /$stimulation.

respectively. The maximal acid secretory response to field stimulation was somewhat lower than that induced by vagal stimulation.

Effects of tetrodotoxin, hexamethonium and atropine on the vagally or field-electrically stimulated supramaximal $(10 \mathrm{~Hz})$ secretion are summarized in Table 1 . Both vagally and field-electrically stimulated acid secretions were completely inhibited by tetrodotoxin $(0.3 \mu \mathrm{M})$ or atropine $(1 \mu \mathrm{M})$. Hexamethonium $(100 \mu \mathrm{M})$ completely

Table 1. Effects of tetrodotoxin, hexamethonium and atropine on vagally and field-electrically stimulated acid secretion in the isolated mouse whole stomach

\begin{tabular}{lcccccc}
\hline & \multirow{2}{*}{$\begin{array}{c}\text { Dose } \\
\end{array}$} & \multicolumn{2}{c}{ Vagal $(10 \mathrm{~Hz})$} & & \multicolumn{2}{c}{ Field $(10 \mathrm{~Hz})$} \\
\cline { 6 - 7 } \cline { 6 - 7 } & & value & $\begin{array}{c}\text { inhibition } \\
(\%)\end{array}$ & & value & $\begin{array}{c}\text { inhibition } \\
(\%)\end{array}$ \\
\hline Control & - & $103.9 \pm 4.7$ & - & & $76.4 \pm 6.8$ & - \\
Tetrodotoxin & 0.3 & $-3.3 \pm 3.2^{* * *}$ & 103 & & $-3.9 \pm 3.6^{* * *}$ & 105 \\
Hexamethonium & 100 & $6.5 \pm 3.0^{* * *}$ & 94 & & $27.7 \pm 4.4^{* * * * * *}$ & 64 \\
Atropine & 1 & $5.5 \pm 1.0^{* * *}$ & 95 & & $2.3 \pm 1.6^{* * *}$ & 97 \\
\hline
\end{tabular}

Treatment with tetrodotoxin, hexamethonium or atropine was performed $15 \mathrm{~min}$ after the 2 nd vagal stimulation (2VS), and the 3rd vagal stimulation $(10 \mathrm{~Hz})$ or field stimulation $(10 \mathrm{~Hz})$ was applied 10 min after the drug addition. Acid secretion elicited by electrical stimulation is assessed as a percent of the 2VS response and also as an inhibitory percentage against the respective control group. Results each represent the mean \pm S.E.M. of $4-6$ experiments. ${ }^{* * *} \mathrm{P}<0.001$ and ${ }^{* \prime *} \mathrm{P}<0.01$, significant difference from the respective control group and basal secretion (1.2 $\pm 2.9 \%$ of $2 \mathrm{VS}, \mathrm{N}=4)$, respectively (unpaired Student's $t$-test). The averaged increases in acid secretion by $2 \mathrm{VS}$ in all groups were

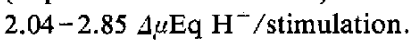


A

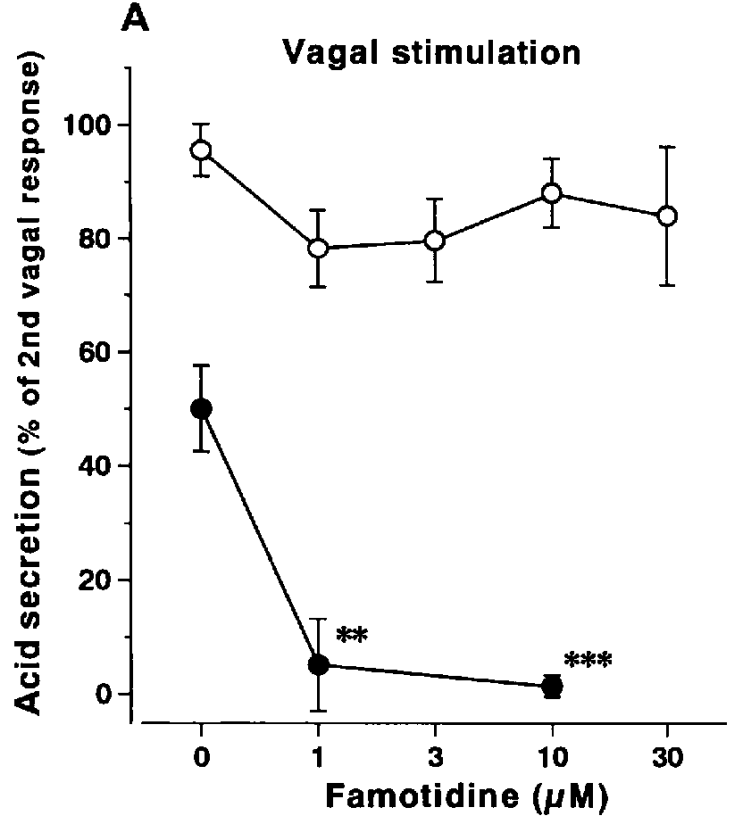

B

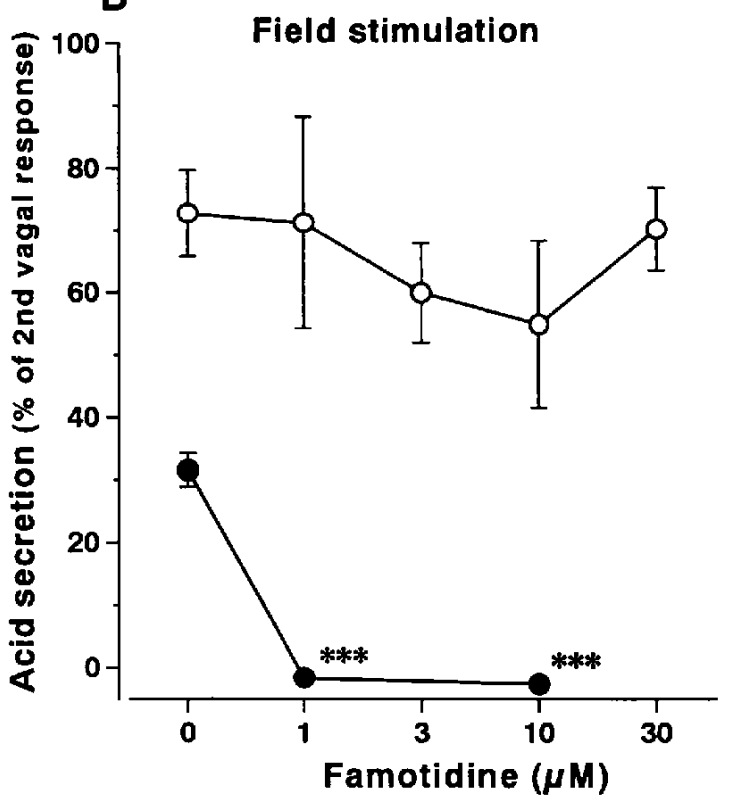

Fig. 4. Effect of famotidine on vagally and field-electrically stimulated $(2 \mathrm{~Hz}$ and $10 \mathrm{~Hz}$ ) acid secretion in the isolated mouse whole stomach. Famotidine (Fam) treatment was performed 15 min after the end of the 2nd vagal stimulation $(2 \mathrm{VS} ; 10 \mathrm{~Hz}$ in common), and the 3rd vagal stimulation or field stimulation was applied $10 \mathrm{~min}$ after the Fam addition. Each curve represents the acid secretion induced by vagal (A) or field-electrical (B) stimulation at $2 \mathrm{~Hz}(\mathrm{O})$ or $10 \mathrm{~Hz}(\mathrm{O})$. Each value is assessed as a percentage of the 2 VS response. Results each represent the mean \pm S.E.M. of 4 experiments. ${ }^{* *} \mathbf{P}<0.01$ and ${ }^{* * *} P<0.001$, significant difference from the respective control (Fam absent) group (ANOVA, followed by Dunnett's test). The averaged increases in acid secretion by $2 \mathrm{VS}$ in all groups were $2.15-3.08 \Delta \mu \mathrm{Eq} \mathrm{H}^{+}$/stimulation.

inhibited the vagally stimulated acid secretion, but partly depressed the field-electrically stimulated acid secretion.

\section{Effect of famotidine on vagally and field-electrically stimulated acid secretion}

Typical patterns of effects of famotidine on the vagally and field-electrically stimulated secretion are shown in Fig. 1 and the results are summarized in Fig. 4. Famotidine $(1-30 \mu \mathrm{M})$, of which the concentrations were $30-1000$ fold higher than the $\mathrm{pA}_{2}$ values estimated above, tended to inhibit the vagally and field-electrically stimulated supramaximal $(10 \mathrm{~Hz})$ secretions, but the inhibition was maximally about $20 \%$. This tendency was not changed by prolongation of incubation time from $10 \mathrm{~min}$ to $50 \mathrm{~min}$; the values of the $3 \mathrm{rd}$ vagal response in the absence or presence of $30 \mu \mathrm{M}$ famotidine was $85.2 \pm 7.7 \%$ $(\mathrm{N}=4)$ or $73.1 \pm 9.0 \%(\mathrm{~N}=4)$ of the 2 nd vagal response, respectively (14\% inhibition), suggesting that after 10 min, further incubation with famotidine does not affect the strength of incubation.

The vagally and field-electrically stimulated submaximal $(2 \mathrm{~Hz})$ secretions were almost completely inhibited by famotidine ( 1 and $10 \mu \mathrm{M}$ ), and greater than $90 \%$ inhibition was obtained even at $1 \mu \mathrm{M}$ of famotidine (Fig. 4). In the presence of neostigmine $(30 \mathrm{nM})$, which did not affect basal acid output, the vagally stimulated submaximal $(2 \mathrm{~Hz})$ secretion tended to increase, as compared with the absence of neostigmine (the former, $71.6 \pm 5.7 \%$ versus the latter, $50.1 \pm 7.5 \%$ of the 2 nd vagal response, $\mathrm{P}<0.1, \mathrm{~N}=4$ ) (Figs. 4 and 5). However, the vagally stimulated supramaximal $(10 \mathrm{~Hz})$ secretion was not affected by the presence or absence of neostigmine. Famotidine $(10 \mu \mathrm{M})$ only moderately inhibited the $2 \mathrm{~Hz}$ vagally stimulated acid secretion in the presence of neostigmine (Fig. 5B). On the other hand, the $10 \mathrm{~Hz}$ vagally stimulated acid secretion was not affected by famotidine in the presence of neostigmine.

Effects of histamine and famotidine on bethanechol induced acid secretion

Histamine $(1 \mu \mathrm{M})$, which did not affect basal secretion, significantly shifted the dose-response curve of bethanechol induced acid secretion leftward, but the maximal acid response to bethanechol was not modified (Fig. 6). In contrast, famotidine $(10 \mu \mathrm{M})$ shifted the dose-response curve of bethanechol induced acid secretion rightward, but the maximal acid response to bethanechol was not changed (Fig. 6). 

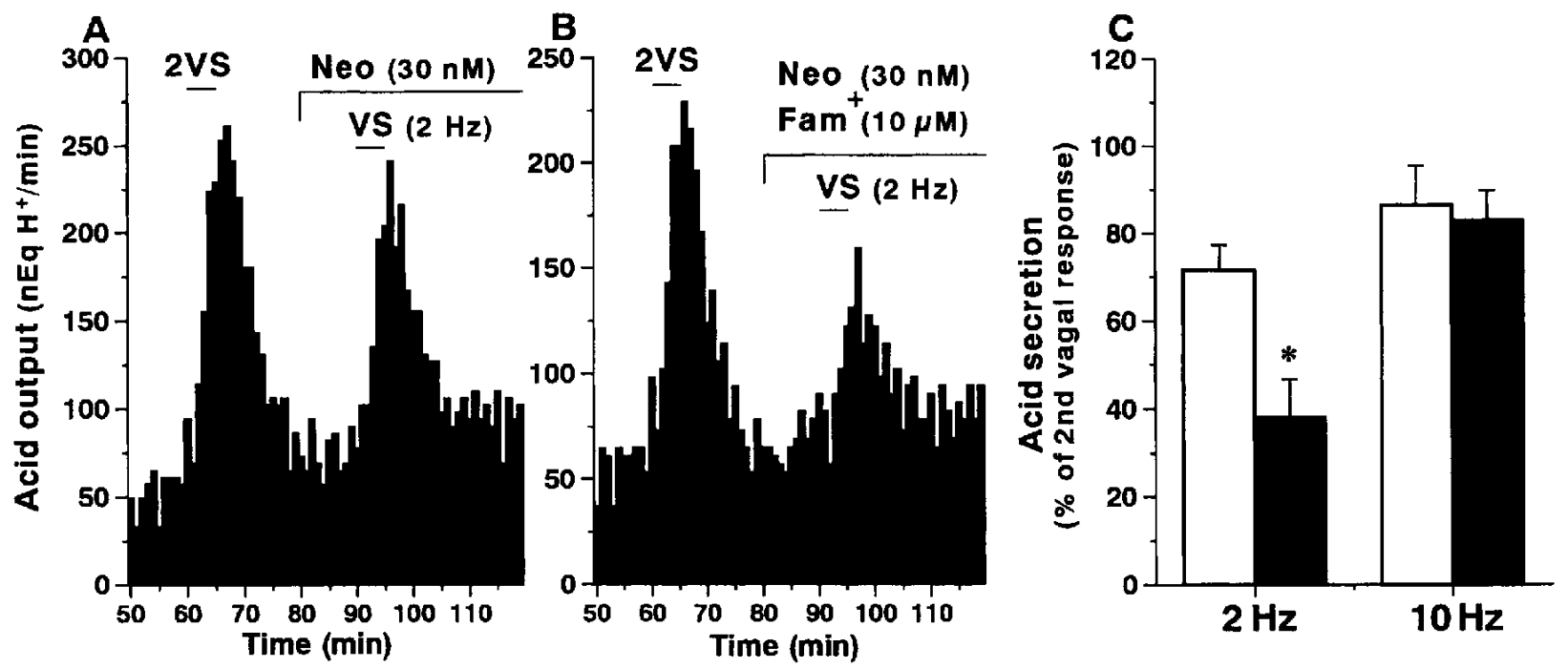

Fig. 5. Effect of famotidine on vagally stimulated $(2 \mathrm{~Hz}$ and $10 \mathrm{~Hz})$ acid secretion in the presence of neostigmine in the isolated mouse whole stomach. Neostigmine ( $\mathrm{Neo}, 30 \mathrm{nM}$ ) and famotidine (Fam, $10 \mu \mathrm{M}$ ) treatment was performed 13 and $15 \mathrm{~min}$ after the end of the 2 nd vagal stimulation (2VS, $10 \mathrm{~Hz}$ in common), respectively, and the $3 \mathrm{rd}$ vagal stimulation (VS) was applied 10 min after the Fam addition. A and B: Typical patterns of acid secretion induced by the $2 \mathrm{~Hz}$ vagal stimulation with Neo in the absence and presence of Fam, respectively. The histogram represents the acid output for $1 \mathrm{~min}$. C: Each value is assessed as a percentage of the 2VS response: Control (open column) and Fam, $10 \mu \mathrm{M}$ (closed column). Results each represent the mean \pm S.E.M. of 4 experiments. ${ }^{*} \mathrm{P}<0.05$, significant difference from the respective control (Fam absent) group (unpaired Student's $t$-test). The averaged increases in acid secretion by $2 \mathrm{VS}$ in all groups were $1.61-2.58 \Delta \mu \mathrm{Eq} \mathrm{H}^{+} /$stimulation.

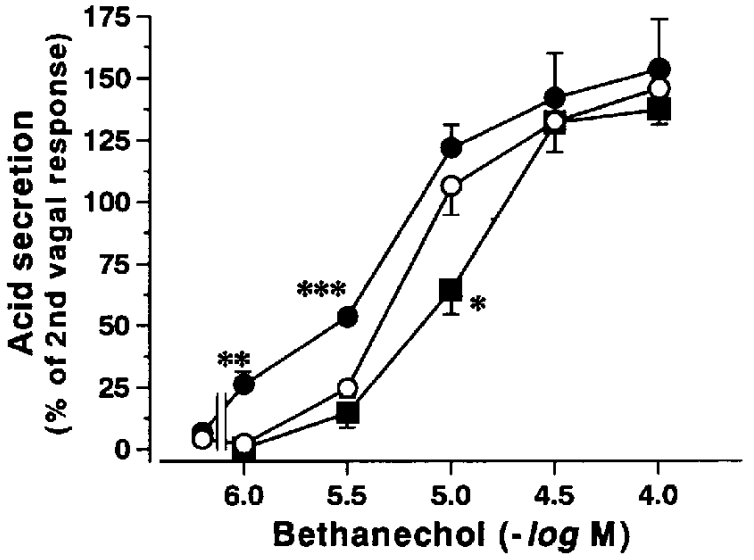

Fig. 6. Effects of histamine and famotidine on bethanechol-induced acid secretion in the isolated mouse whole stomach. Histamine (Hist, $1 \mu \mathrm{M}$ ) or famotidine (Fam, $10 \mu \mathrm{M}$ ) treatment was performed $15 \mathrm{~min}$ after the end of the $2 \mathrm{nd}$ vagal stimulation (2VS), and bethanechol was applied $10 \mathrm{~min}$ after the Hist or Fam addition. Dose-response curves represent the acid secretion induced by bethanechol in the absence $(O)$ or presence of Hist $(O)$ or Fam $(\square)$. Each value is assessed as a percentage of the 2 VS response. Results each represent the mean \pm S.E.M. of $4-6$ experiments. ${ }^{*} \mathrm{P}<0.05$, ${ }^{* *} \mathbf{P}<0.01$ and ${ }^{* * *} \mathbf{P}<0.001$, significant difference from the respective control group (unpaired Student's $t$-test). The averaged increases in acid secretion by $2 \mathrm{VS}$ in all groups were $1.57-2.75 \Delta \mu \mathrm{Eq} \mathrm{H} \mathrm{H}^{+}$ stimulation.

\section{DISCUSSION}

Electrical stimulation of the vagus nerve caused a quantitative and reproducible increase in acid secretion in the mouse whole stomach preparation. Our stomach preparation responded to both direct activation of muscarinic receptors by cholinergic stimulants and neuronal activation by electrical stimulation. In the case of field stimulation, the secretory response probably occurs under more complicated neuronal conditions $(8,10,11)$, since the stimulation is capable of acting on all kinds of neurons including the vagus nerves and sympathetic nerves, regardless of whether they are pre- or post-synaptic fibers. So, we first tried to develop a method for specifically stimulating the vagus nerves by setting the electrodes at the lower level of the esophagus. This vagally stimulated acid response was completely inhibited by hexamethonium or atropine, suggesting that the vagal response was elicited by selective stimulation of the parasympathetic pre-ganglionic fibers. However, the acid secretory response to field stimulation was completely inhibited by atropine but partly refractory to hexamethonium, suggesting that the field-electrical response was at least partly evoked through the post-ganglionic fibers of cholinergic neurons, although this finding is discrepant from the previous report by others (8) that the field stimulation response was completely abolished by hexamethonium. 
On the other hand, though most of previous investigators isolated the stomach after killing by cervical dislocation, we found that the vagal secretory response of the stomach isolated after killing by bleeding was significantly depressed as compared with the stomach isolated under anesthesia. This phenomenon was also found in histamine-induced acid secretion, suggesting that the reduced secretory responsiveness originates in the parietal cell itself. Although only $10 \mathrm{~min}$ are taken for the isolation procedure, the short-time anoxia might influence the subsequent secretory responses; therefore, stomach isolation under anesthesia was conducted in the present study.

The vagally and field-electrically stimulated acid secretions were frequency-dependent. Black and Shankley (16) reported that the field stimulation under physostigmine treatment could evoke stable acid secretion in mice by cumulatively increasing frequency (the cumulative method). In their experimental condition without physostigmine, however, unstable responses with an initial peak were often observed during continuous stimulation (8). In spite of this fact, they also evaluated the secretory response to the field stimulation by the cumulative method. Moreover, the cumulative method may include time-dependent changes in the secretory response. In fact, the vagally stimulated acid secretion did not maintain its maximal response for more than $20 \mathrm{~min}$ in frequent cases.

Secretagogue induced acid responses were also observed in this preparation. The response to each secretagogue was characterized by a different secretory pattern. In the case of bethanechol, the increased response was gradually reduced $20 \mathrm{~min}$ to $40 \mathrm{~min}$ after treatment; therefore, the cumulative method was not suitable for testing the effect of drugs that are not like histamine. The $\mathrm{pA}_{2}$ value (7.82) estimated from atropine-bethanechol antagonism in the mouse stomach is consistent to that previously reported by others (14). However, this value is significantly lower than the $\mathrm{pA}_{2}$ value (8.98) that is estimated against guinea pig longitudinal ileum contraction. The reason for such a difference is unknown, but some investigators suspect that the steady-state loss of atropine into the mucosal perfusate results in a lower concentration of the antagonist at the receptor site $(14,17)$.

Cimetidine was most frequently used as a reference $\mathrm{H}_{2}$ antagonist in the pharmacological experiments. However, we previously found that cimetidine had a non-specific (probably anti-muscarinic) antisecretory effect (13). Some reports also showed that cimetidine and ranitidine had pharmacological effects different from $\mathrm{H}_{2}$-antagonism $(18,19)$. Famotidine probably is a relatively pure $\mathrm{H}_{2-}$ receptor antagonist compared with the above two drugs; therefore, we preferred to use famotidine as an $\mathrm{H}_{2}$-antagonist to clarify the role of endogenous histamine on the vagally or field-electrically stimulated acid secretion.
Some previous investigators reported that the acid secretion induced by electrical field stimulation was completely inhibited by $\mathrm{H}_{2}$-receptor blockade, even though the stimulation frequency was changed broadly $(8,10)$. This is very different from the present finding that the vagally and field-electrically stimulated supramaximal (10 $\mathrm{Hz}$ ) secretions were only slightly inhibited by famotidine even at a concentration of $30 \mu \mathrm{M}$, which is approximately 1000 -fold higher than the $\mathrm{pA}_{2}$ value estimated from histamine-famotidine antagonism. Therefore, we consider that the vagal (and also field) stimulation, under an intensely stimulating condition of $10 \mathrm{~Hz}$, can directly activate the muscarinic receptors on parietal cells and, therein, acid secretion is maximally evoked without the aid of histamine mediation. However, the vagally and field-electrically stimulated submaximal $(2 \mathrm{~Hz})$ secretions were almost completely abolished by $1 \mu \mathrm{M}$ of famotidine in our experimental condition.

Regarding the histamine mediation, Black and co-workers $(3,12)$ have reported many interesting findings using the mouse stomach assay. They finally proposed that the muscarinic receptor density on histamine containing cells is higher than that located on parietal cells. On the other hand, in their experimental condition, the field-electrically $(1-30 \mathrm{~Hz})$ stimulated acid secretion in mice was completely abolished by $\mathrm{H}_{2}$-antagonist such as tiotidine (8). Their results and hypothesis, however, could be explained by the idea of submaximal $(2 \mathrm{~Hz})$ and supramaximal $(10$ $\mathrm{Hz}$ ) nerve stimulation that is shown in our present study. Namely, the amount of acetylcholine released by low frequency stimulation is probably small, indicating that only muscarinic receptors on histamine containing cells are activated, while that of acetylcholine released by high frequency stimulation is probably abundant, indicating that both muscarinic receptors on histamine containing cells and parietal cells are activated and thus, the acid secretory response is hardly influenced by an $\mathbf{H}_{2}$-antagonist. This possibility is supported from the present result that in the presence of neostigmine, the $2 \mathrm{~Hz}$ vagally stimulated acid secretory response was partly refractory to famotidine and also from the original findings of Black and Shankley (12) showing refractoriness to tiotidine under physostigmine treatment. In this case, the concentration of acetylcholine at the receptor site by the $2 \mathrm{~Hz}$ vagal stimulation is expected to be higher than in the absence of neostigmine; therefore, the muscarinic receptors on parietal cells are also partly activated. Although it is not clear why there exists such a discrepancy in the effect of an $\mathrm{H}_{2}$-antagonist between our results and the findings of others, a possibility remains that this might be caused by differences in the experimental designs and stomach isolation methods.

There exists a possibility that the acid secretory 
response to cholinergic stimulation is potentiated by concurrently released histamine. In the present study, bethanechol induced acid response was shifted rightward by a high dose of famotidine and leftward by a low dose of histamine, although the maximal acid response was not changed by either of the treatments. The similar results with $\mathrm{H}_{2}$-antagonists were previously reported by others (20); and thus, it is deduced that relatively weak cholinergic stimulation activates only the muscarinic receptor on histamine containing cells. On the other hand, the present results with histamine may suggest that histamine has a simple synergistic effect. However, this finding was not consistent to the results obtained in isolated canine parietal cells (21) where aminopyrine accumulation was potentiated by the combination of carbachol and histamine or dibutyryl cyclic-AMP, with an increase in the maximal response. The reason for this difference is unknown, but further studies are needed to establish adequate experimental conditions including selection of appropriate doses of histamine for the mouse stomach assay.

It is physiologically important to think about the possibility that intense secretory responses through muscarinic receptors on parietal cells take place in whole animals as well as in isolated mouse stomach. The acid response to centrally acting secretagogues such as 2-deoxy-D-glucose (2DG) and kainic acid is well-known to stimulate acid secretion exclusively through the vagal pathway. In the literature, the response to intravenous 2DG was partly inhibited by $\mathrm{H}_{2}$-antagonists in rats (22). In our laboratory, the response to intracerebroventricular kainic acid $(0.1$ or $1 \mu \mathrm{g} / \mathrm{rat})$ was inhibited by $83 \%$ or $11 \%$, respectively, after famotidine $(1 \mathrm{mg} / \mathrm{kg}$, i.v.) in anesthetized rats (unpublished data, K. Watanabe et al.). Accordingly, these findings strongly suggest that the extent of the blocking effect of $\mathrm{H}_{2}$-antagonists is closely associated with the strength of the acid secretory response to cholinergic stimulation.

In conclusion, it is suggested that the vagally stimulated acid secretory responses in our isolated mouse whole stomach preparation are evoked by two distinct processes. One is mediation of histamine released from histamine-containing cells that occurs with relatively weak stimulation, and the other is direct activation of muscarinic receptors on parietal cells that occurs with relatively strong stimulation.

\section{Acknowledgments}

This study was supported in part by a Grant-in-Aid for Scientific Research from the Ministry of Education, Science, Sports and Culture of Japan and by a grant for scientific research from the President of Chiba University.

\section{REFERENCES}

1 Rangachari PK: Histamine: mercurial messenger in gut. Am $\mathbf{J}$ Physiol 262, G1-G13 (1992)

2 Code CF: Reflections on histamine, gastric secretion and the $\mathrm{H}_{2}$ receptor. New Engl J Med 296, 1459-1462 (1977)

3 Black J: Reflections on the analytical pharmacology of histamine $\mathrm{H}_{2}$-receptor antagonists. Gastroenterology 105, 963-968 (1993)

4 Wilkes JM, Kajimura M, Scott DR, Hersey SJ and Sachs G: Muscarinic responses of gastric parietal cells. J Membr Biol 122, 97- 110 (1991)

5 Soll AH: Secretagogue stimulation of $\left[{ }^{14} \mathrm{C}\right]$ aminopyrine accumulation by isolated canine parietal cells. Am J Physiol 238, G366-G375 (1980)

6 Pfeiffer A, Rochlitz H, Herz A and Paumgartner G: Stimulation of acid secretion and phosphoinositol production by rat parietal cell muscarinic $M_{2}$ receptors. Am J Physiol 254, G622-G629 (1988)

7 Wan BYC: Metiamide and stimulated acid secretion from the isolated non-distended and distended mouse stomach. J Physiol (Lond) 266, 327-346 (1977)

8 Welsh NJ, Shankley NP and Black JW: Comparative analysis of the vagal stimulation of gastric acid secretion in rodent isolated stomach preparations. Br J Pharmacol 112, 93-96 (1994)

9 Horie S, Yano S and Watanabe K: Differential effects of $\mathrm{Na}^{+}$, $\mathrm{K}^{+}$-ATPase inhibition by ouabain on acid secretory response to histamine and bethanechol in the mouse isolated stomach. Br J Pharmacol 112, 87-92 (1994)

10 Angus JA and Black JW: The interaction of choline esters, vagal stimulation and $\mathrm{H}_{2}$-receptor blockade on acid secretion in vitro. Eur J Pharmacol 80, 217-224 (1982)

11 Kromer W, Baron E, Boer R and Eltze M: Telenzepine inhibits electrically-stimulated, acetylcholine plus histamine-mediated acid secretion in the mouse isolated stomach by blockade of $\mathrm{M}_{1}$ muscarine receptors. Naunyn Schmiedebergs Arch Pharmacol 343, 7-13 (1991)

12 Black JW and Shankley NP: How does gastrin act to stimulate oxyntic cell secretion? Trends Pharmacol Sci 8, 486-490 (1987)

13 Watanabe $K$, Yano S, Yamamoto $M$ and Kanaoka S: Comparative effects of cimetidine and famotidine on the vagally stimulated acid secretion in the isolated mouse whole stomach. Jpn J Pharmacol 61, 229-236 (1993)

14 Angus JA and Black JW: Analysis of anomalous $\mathrm{pK}_{\mathrm{B}}$ values for metiamide and atropine in the isolated stomach of the mouse. Br J Pharmacol 67, 59-65 (1979)

15 Black JW, Less $P$ and Shankley NP: Further analysis of anomalous $\mathrm{pK}_{\mathrm{B}}$ values for histamine $\mathrm{H}_{2}$-receptor antagonists on the mouse isolated stomach assay. Br J Pharmacol 86, 581-587 (1985)

16 Black JW and Shankley NP: Pharmacological analysis of the inhibition by pirenzepine and atropine of vagal-stimulated acid secretion in the isolated stomach of the mouse. Br J Pharmacol 88, 291-297 (1986)

17 Angus JA, Black JW and Stone M: Estimation of $\mathrm{pK}_{\mathrm{B}}$ values for histamine $\mathrm{H}_{2}$-receptor antagonists using an in vitro acid secretion assay. Br J Pharmacol 68, 413-423 (1980)

18 Ishikawa T, Kamisaki Y, Omodani H, Houi N, Maeyama K, Watanabe $\mathrm{T}$ and Itoh $\mathrm{T}$ : Inhibitory effects of histamine $\mathrm{H}_{2}$-antagonists on forskolin-stimulated acid production in isolated 
parietal cells. Drug Invest 1, 38-43 (1990)

19 Gwee MCE and Cheah LS: Action of cimetidine and ranitidine at some cholinergic sites: Implications in toxicology and anesthesia. Life Sci 39, 383-388 (1986)

20 Black JW and Shankley NP: Pharmacological analysis of muscarinic receptors coupled to oxyntic cell secretion in the mouse stomach. Br J Pharmacol 86, 601-607 (1985)
21 Soll AH: potentiating interactions of gastric stimulants on $\left[{ }^{14} \mathrm{C}\right]$ aminopyrine accumulation by isolated canine parietal cells. Gastroenterology 83, 216-223 (1982)

22 Shibata $\mathbf{M}$, Yamamura $\mathrm{T}$, Inaba $\mathrm{N}$, Onodera $\mathrm{S}$, Chida $\mathrm{Y}$ and Ohnishi H: Gastric antisecretory effect of FRG-8813, a new histamine $\mathrm{H}_{2}$ receptor antagonist, in rats and dogs. Eur $\mathbf{J}$ Pharmacol 235, 245-253 (1993) 